Noticias

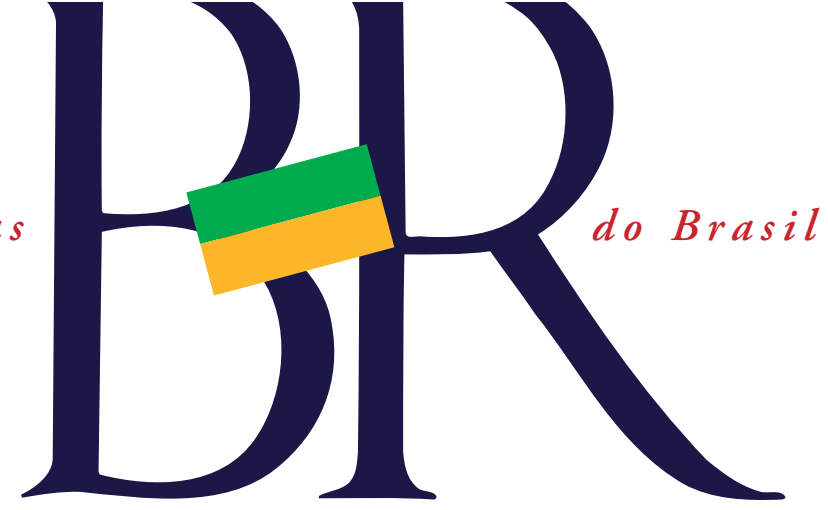

Política de C\&T

\title{
Leis que engessam pesquisa no país podem ser alteradas ainda este ano
}

Até dezembro devem ser votadas uma série de medidas com o objetivo de destravar os processos de ciência, tecnologia e inovação (CT\&I) e tornar o país mais competitivo. A ideia inicial era criar o Código $\mathrm{Na}$ cional de Ciência, Tecnologia e Inovação, o Projeto de Lei 2.177/2011, que alteraria partes de várias leis que travam os pesquisadores, como a concessão de visto temporário a estrangeiros que queiram fazer pesquisa no Brasil (Lei 6.815) e receita do Fundo Nacional de Desenvolvimento Científico e Tecnológico (FNDCT; 11.540). Também revogaria a Lei de Inovação (10.973) e importações de bens destinados à pesquisa (8.010); e afetaria, entre outras, a Lei de Licitaçôes (8.666), a Lei do Bem (11.196) e a Lei de Acesso à Biodiversidade (11.105).

No entanto, para reduzir a rigidez e permitir que os vários subtemas fossem melhor trabalhados, a relatoria da Comissão Especial da Câmara dos Deputados propôs desmembrar o Código em uma Proposta de Emenda Constitucional (PEC), um Regime Diferenciado de Contrataçôes Públicas (RDC), uma legislação específica de Acesso à Biodiversidade e um projeto de lei que incorporasse itens do PL 2.177, Lei de Inovação e outras similares. A intenção é tocar em pontos cruciais para pesquisadores. "Por que o Brasil tem um regime diferenciado de contrataçôes para obras da Copa do Mundo, mas engessa a pesquisa científica? Se o país chegou à conclusão de que a Lei 8.666 não servia para a realização da Copa do Mundo e das Olimpíadas, e fez o RDC para estes eventos, por que não para as universidades?", questionou a presidente da Sociedade Brasileira para o Progresso da Ciência (SBPC), Helena Nader, na audiência pública da comissão especial que analisou a proposta do Código, em maio deste ano (em matéria publicada em maio no JC 4732).

Uma das mudanças mais aguardadas é a flexibilização da questão de compras e contrataçôes, com a retirada da obrigatoriedade da aplicação da Lei das Licitações (8.666/1993) às atividades de CT\&I, que indica que o critério das aquisiçôes seja sempre o menor preço, o que muitas vezes compromete a qualidade da pesquisa, que deve ter insumos adequados
Antonio Perri/Ascom/Unicamp I Antonio PerriAscom/Unicamp

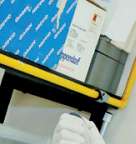

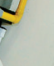
(1) ? 4.

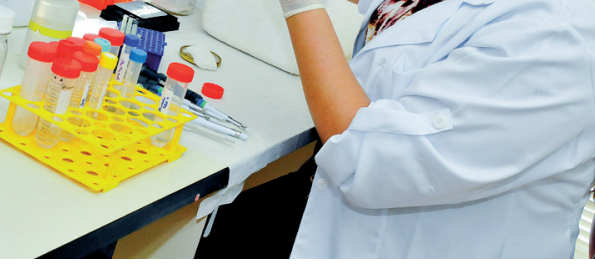

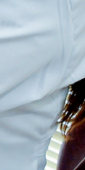

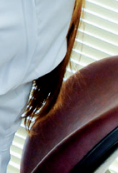

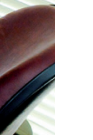
mental requer agilidade

e equipamentos específicos. Nesse sentido, também aparece como entrave a Lei de Importação, que prejudica quem depende de material específico fabricado no exterior.

IMPORTAÇÕES Uma pesquisa conduzida desde 2004 pelo Laboratório Nacional de Células Tronco Embrionárias (LaNCE), do Instituto de Ciências Biomédicas da Universidade Federal do Rio de Janeiro (UFRJ), mostra o impacto da dificuldade de importação sobre o progresso da ciência brasileira.

Os resultados de 2010 apontados por trabalho deram base a um Projeto de Lei do deputado Romário (PSB-RJ) que aguarda deliberação na Comissão de Seguridade Social e Família (CSSF). Uma das propostas é que se faça um cadastro nacional dos pesquisadores que teriam liberação imediata dos materiais da 


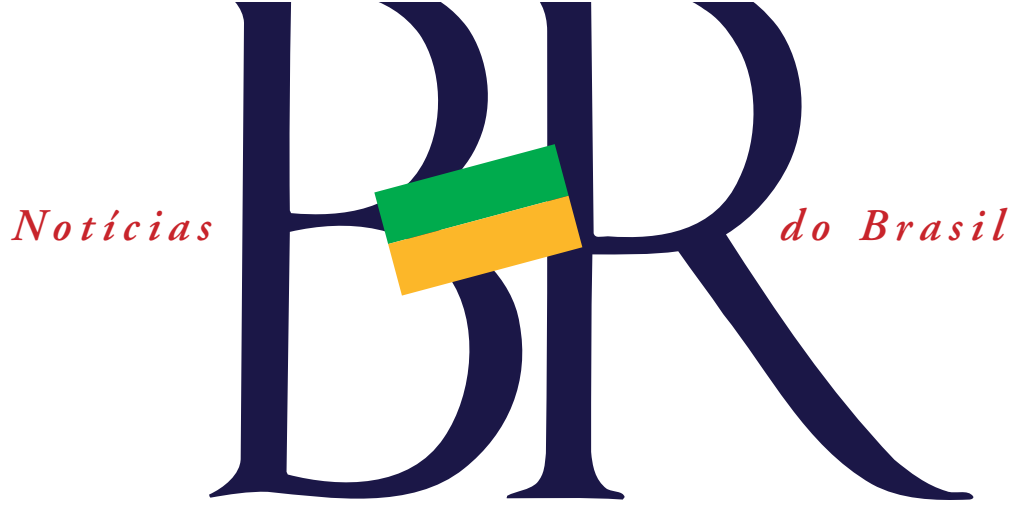

pesquisa. Ele passaria a ter responsabilidade sobre os produtos adquiridos e pelos possíveis danos à saúde individual ou coletiva e ao meio ambiente decorrentes de alteração da finalidade declarada para o ingresso do material.

Extravios, alto custo de transporte e tempo de liberação dificultam a aquisição de substâncias controladas - como solventes, reagentes e medicamentos - e interrompem trabalhos. Para Daniel Veloso Cadilhe, pesquisador do LaNCE, para importar células ou animais é preciso sorte. "Quando as células são liberadas, vêm invariavelmente descongeladas e, portanto, mortas. Certa vez importamos uma carga perecível e esta ficou embargada por dois meses. Perdemos R \$ 30 mil. É dinheiro público gasto em vão que poderia ser revertido em avanço científico", lamenta.

PRESTAÇÃO DE CONTAS Havendo mudança nas legislação, deve mudar também a prestação de contas, pois os Tribunais de Contas, responsáveis pela fiscalização da aplicação dos recursos públicos, realizam mais comumente a auditoria baseada na verificação de cumprimento de leis (e não nos resultados da gestão). Em sua tese de doutorado, recentemente defendida no Instituto de Geociências da Universidade Estadual de Campinas (Unicamp), Maristella Barros Ferreira de Freitas, apontou a existência de um ambiente de inse- gurança na gestão de CT\&I, causada pelas imperfeições e a rigidez das legislações, que afeta todo o processo científico e tecnológico.

Além das imprecisóes e obscuridades das legislações específicas (que resultam em divergência de interpretações), outro agravante é o fato de $o$ instrumento utilizado para fiscalização pelos Tribunais de Contas ser a auditoria de conformidade - também conhecida como auditoria de regularidade. Esse tipo de controle prioriza a verificação do cumprimento de disposiçôes legais em detrimento da avaliação de resultados.

$\mathrm{O}$ julgamento resulta em determinações de natureza punitiva. São as medidas cautelares (afastamento temporário do responsável, indisponibilidade ou arresto de bens e suspensão de ato ou procedimento) e sancionadoras (aplicação de multas, ressarcimento de valores e inabilitação do responsável por um período de 5 a 8 anos para o exercício de cargo em comissão ou função de confiança na administração pública). "Diante de perspectivas tão ameaçadoras, é natural o sentimento de medo e insegurança dos pesquisadores e gestores públicos. Nesse cenário, assumir um cargo público nessa área ou gerenciar recursos públicos para P\&D passou a ser uma tarefa de risco pessoal", aponta Freitas.

Nem sempre as exigências legais se aplicam à realidade do ambiente de CT\&I. É o caso de contratação tem- porária de pesquisadores sem concurso público. "Criar mecanismos de identificação de pontos fracos e de pontos fortes na gestão das atividades de CT\&I e P\&D, apontariam para soluções de controle mais eficientes para atingir o almejado desenvolvimento científico e capacitação tecnológica", afirma a pesquisadora.

MODELOS Um bom exemplo, segundo ela, é o que fazem o GAO (Escritório de Contabilidade do Governo) e o NAO (Escritório Nacional e Auditoria), entidades fiscalizadoras dos Estados Unidos e do Reino Unido, respectivamente. Nesses países a fiscalização da aplicação de recursos públicos se dá mediante performance auditing, que nos Tribunais de Contas do Brasil é chamado auditoria operacional. Essa auditoria tem mais flexibilidade na escolha dos objetos e na forma de comunicar suas conclusões. Baseada em normas internacionais, requer do auditor flexibilidade, imaginação e capacidade analítica. Assim, mesmo com mudanças no marco legal da pesquisa científica no Brasil, seria adequado que a auditoria de conformidade fosse utilizada apenas na fiscalização das áreas "meio" (apoio administrativo, infraestrutura, previdência de inativos, amortização e encargos da dívida interna, cumprimento de sentenças judiciais).

Marina Gomes 